\title{
Determination Prevalence Of Clinical Patterns Of Alopecia Areata In Relation To Some Varieties In Kerman Iran
}

\author{
S Shamsadini, S Eshkavary, V Sepehr
}

\section{Citation}

S Shamsadini, S Eshkavary, V Sepehr. Determination Prevalence Of Clinical Patterns Of Alopecia Areata In Relation To Some Varieties In Kerman Iran. The Internet Journal of Dermatology. 2005 Volume 3 Number 2.

DOI: $\underline{10.5580 / 212 \mathrm{f}}$

\begin{abstract}
Introduction: Alopecia areata has different clinical presenting patterns, it may starts with a self limited single or separated patches on the scalp or any area of the body and progressing to complete scalp hair loss or complete body hair loss.

Objective:Determination prevalence of alopecia areata with clinical configurations of patients in this area and its comparison with similar studies in other parts of the world that is the base and its localization to scalp or body in relation to skin color and nail ridging or cryptic dental infection or carries.
\end{abstract}

Method: 952 patients with alopecia areata were studied who has been found among of 25186 new patients in this study that had been referred from all around the Kerman a province of Iran, as out patient during 3 years by the major points of age, sex, family history, extent percent of involved area \& history of any determined infection such as nail ridges and dental caries or infections who were

variables that has been evaluated in this study.

Results: $3.78 \%$ of all new dermatology patients had alopecia areata. Family history was seen in $3.6 \%$ of patients and male to female ratio was 2.6 \& the commonest clinical patterned were either round or oval types. Hair loss configurations in 252 patients (26.5\%) were only restricted to scalp, in 216 cases $(22.7 \%)$ to body, and in 414 cases $(50.8 \%)$ was seen in both scalp \& body (bipolar) alopecia areata. Bipolar type of alopecia areata was seen mostly in the first 3 decades of life which shows a significant difference in compare to the other configurations $(p<0.01)$.

Conclusion: Prevalence of alopecia areata between new dermatologic patients during 3 years was as $3.78 \%$. Body hair loss (bipolar type) in males and a the first 3 decades of age were significantly more than females and those who were in upper 3 decades of age respectively.

\section{INTRODUCTION}

Alopecia areata first time was described by a physician named as Cornelius Celsus (30 Before Christ). Even now this disease is sometimes called as Celsus alopecia. Celsus has named this disorder as ophiasis $\left({ }_{1}, 2,3\right)$. Nowadays, Ophiasis has been known as a type of alopecia areata. Alopecia areata is a common cause of non-scaring alopecia characterized known by patchy hair loss $(4,5)$. In some patients the disease progresses and new types of alopecia appear ending to alopecia totalis or alopecia universalis $(4,6,7)$. Alopecia areata has many variables and clinical manifestations, from a single patch on the scalp or body area to complete body alopecia. The disease can also show itself with generalized fine scalp hair without any localized hair loss $\left({ }_{8}, 9\right)$. Hair loss can be the only visible clinical sign or accompanied with nail disorders. With determining the comprehensive clinical patterned of the patients with alopecia areata, it can be compared with other local statistic results $\left({ }_{1,7}, 10\right)$. Even though, other laboratory findings have also been used in the evaluation of alopecia areata, but clinical information has basic significance in diagnosing $\&$ classifying this disease $\left({ }_{11},{ }_{12},{ }_{13}\right)$. Hair loss occurs in the forms of round or oval with sharply defined bald patches $\left({ }_{14}, 15\right)$. The main characteristic of the disease is the presence of follicular 
marking in the lesions. The involved area has no scaling, hardness \& follicular markers. The spread of the disease can start from a localized form and can be end to complete scalp or body hair loss and or nail involvement. The disease may be progressive or non-progressive $\left({ }_{11,16,17}\right)$. In this study, a cross sectional study has been done on determination prevalence of alopecia areata patterned in Kerman a southern province of Iran.

\section{MATERIAL \& METHODS}

For each alopecia areata patient referred to the dermatology out patient clinics of Kerman during 3 years from May 2000-2003, separate files were made .The diagnosis of the disease was done on the basis of the clinical signs. Those cases which were suspicious or needed more investigation or their hair loss was not obvious clinically were omitted from the study. These information included: individual characteristics, date for referral, patient's age at the time of referral, age at the onset of the disease, duration of the present episode, the extent of spread $\&$ the involved area. Definitions: Types of alopecia areata with skin and hair color were determined according to the following:

Alopecia areata: A common type of localized hair loss that the percent of hair loss in a part is $<99 \%$.

Alopecia totalis: When the hair of a part of body (scalp, face, trunk and limbs) is completely lost.

Alopecia totalis/universalis: Indicates the total loss of scalp hair or non scalp body and or a part of the body hair.

Alopecia universalis: When all scalp \& body hair is lost.

Determination of extent bald areas in scalp is determined by this way: the scalp is divided into 4 quarters. The percent of all the areas of alopecia in all parts was estimated as if all the bald parts were put together scalp hair loss was divided into 5 degrees: $\mathrm{S} 0=$ no scalp hair loss, $\mathrm{S} 1=<25 \%$ scalp hair loss, $\mathrm{S} 2=26-50 \%$ scalp hair loss, $\mathrm{S} 3=51-99 \%$ scalp hair loss, $\mathrm{S} 4=100 \%$ scalp hair loss. Body hair loss also was divided into 5 degrees: $\mathrm{B} 0=$ no body hair loss, $\mathrm{B} 1=<25 \%$ body hair loss, $\mathrm{B} 2=26-50 \%$ body hair loss, $\mathrm{B} 3=51-99$ body hair loss, B4 $=100 \%$ body hair loss. Nail exams described 2 steps: N0: means not involved nail, N1:= nail involved.

Skin color: our patient settled of this character in two groups: first light skin (contain type of I, II \& III) and second dark skin (contain type IV, V \&VI) of skin color classification of sun protective skin typing $\left({ }_{14}\right)$. Scalp hair colors of our patients engaged in two groups: light scalp hair (contains tan and blond hair) which the densest hair pigment is eumelanin and dark scalp hair (contain black hair and dark brown hair) which base pigment material in their shaft hair is pheomelanin. $\left({ }_{18,19,20}\right)$

\section{RESULTS}

The study was done on 956 patients with alopecia areata who were found out of 25186 new dermatology patients during 3 years in a dermatology center, whom comprised as $3.78 \%$. The average age was 23 years $(24.5$ years in males \& 19 years in females). Male to female ratio was 2.6 to 1 and prevalence of familial involvement history was 3.6\%.The commonest clinical presentation were round and oval configurations. 484 (50.8\%) of our patients had association of alopecia areata of scalp \& body (bipolar type) simultaneously. Sexual predomination was seen as 355 males $(73.3 \%)$ and 129 females $(26.7 \%)$. Body hair loss alone in males were significantly more than females. Sites of hair loss according to the sexes are shown in Table 1. Prevalence of scalp and or body hair loss in compare to those bipolar scalp and body hair loss was seen in aged group, while bipolar configurations were seen more in the first decade of age ( $<<0.001 \&$ X2=9.8) (Table 2). Out of 824 cases who had scalp dark hair 349 cases $(42.4 \%)$ had bipolar alopecia areata of scalp and body. 275 cases $(33.3 \%)$ had only scalp hair loss and the remained 200 cases $(24.3 \%)$ complained of alopecia areata in body alone. While out of 112 cases with light hair 49 cases $(43.8 \%)$ complained of bipolar scalp and body hair loss since 24 cases $(21.4 \%)$ had exclusive scalp hair loss and 39 cases $(34.8 \%)$ had only exclusive body hair loss. The difference between them was significant ( $\mathrm{p}<0.01 \& \mathrm{X} 2-8.8$ ). Amongst 152 patients with light color skin 72 cases had localized hair loss in both scalp and body, 32 cases had exclusive alopecia areata of scalp, the remaining 48 cases had exclusive localized body hair loss only.

Out of 624 patients with semi-dark skin, 246,203\&175 cases complained of combined, exclusive scalp \& exclusive body hair loss respectively. Out of 176 cases with dark skin $96,64 \& 16$ persons complained of combined, exclusive scalp $\&$ exclusive body hair loss respectively $(\mathrm{p}<0.001 \&$ $\mathrm{X} 2=26.8$ ). The previous pattern of the extent of hair loss in scalp or body in the patients is shown in Table 3 .

Nail changes and their association with extension of hair loss was significantly more in those with scalp hair loss $(p<0.001, X 2=9.0)$.(Table 4). The number of decayed teeth in 
relation to the site of hair loss is shown in Table 5. There was a significant relationship between the body hair loss \& the number of decayed teeth of the patient $(\mathrm{p}<0.01, \mathrm{X} 2$ =19.6). Hairloss of eyebrows \& eyelashes were seen in 153 $\& 137$ patients, respectively and 105 cases complained of hair loss of both side of eyebrows \& eyelashes. Alopecia areata were seen with association of atopic dermatitis, vitiligo, wart \& pityriasis alba in $32,24,24 \& 8$ patients, respectively.

\section{DISCUSSION}

Alopecia areata has different incidence in different racial kinds and geographical areas of the world, and estimated between $0.5-1 \%$ of general population $\left({ }_{5,9}\right)$. In our study it's prevalence was $3.78 \%$ among new dermatologic patients who has been referred to a dermatology clinic in Kerman. Family history involvement in this study found as 3.6\%, who is near the prevalence of it in Italians patients, which found as $4 \%\left({ }_{16}, 20,21\right)$ but we think that the reliability of taking history about family involvement in our patients been controversially and may be more than this, because many of our patients had not enough information about affected cases in their far family relatives. The prevalence of family history has been reported $27 \%$ in Cleveland of U.S.A., $24 \%$ in U.K., $22 \%$ in France, $20 \%$ in Scotland, $18 \%$ in Holland $6.3 \%$ in Poland, $6 \%$ in Portugal, but no evidence of genetic factors in Spain $\left({ }_{1,2}, 6,16\right)$. The drastic difference in these numbers is an indicator of the difference in the trial to search the family history and its report. The inheritance model seems to be autosomal dominant with variant penetration. The racial factors may also have an important role in the prevalence of the disease. Arnold realized that alopecia areata is significantly commoner in the Japanese residing in Hawaii $\left({ }_{12},{ }_{16}, 22\right)$. The site of alopecia areata in scalp and/or body had a significant association at the onset of disease but not in harmony (Table 2). The average age of onset in our study was 23 years (24.5 years in males \& 19 years in females), which showed earlier onset in females. Short and uncovered scalp hair and soon appears hair loss of males in compare to females in our social can be one of causes of earlier referring to physician. Male to female ratio in this study was 2.6 to 1 which is almost close to the obtained statistics ( 2 over 1 ) in the study that has been done by Valikhani M \& colleagues on Tehrani patients (capital of Iran) $\left(_{10}\right)$. Seiter $\mathrm{S}$ et al and Madani $S$ et al in separated study reported that male to female ratio were equal $\left({ }_{3}, 5,23\right)$. Although causes of increasing male to female ratio in both studies of Iran are not known but we can think about physiologic lack of hair in beard \& mustache in females in compare to males and also short and uncovered scalp hair in males may cause soon appearing and referring more to dermatology clinic than female. Frequency of sex ratio in alopecia areata varied in different area so, in a study who has done on patients with alopecia areata in England (2002-2003) showed 31\% of hospital consultant episodes of alopecia areata were for men and remain $69 \%$ were for women $\left({ }_{4,8}\right)$. A significant association was observed between alopecia areata in scalp and/or body and the sex character of our patients. (Table1). More than half of our patients $(50.8 \%)$ complained of sudden bipolar scalp \& body alopecia areata. Frequency of alopecia areata in scalp limited only and body limited alone showed that were with higher of mean age, while bipolar types was significantly observed more in the first 3 decades of life and also body hair loss due to alopecia areata in males was significantly higher than females ( $<<0.01 \& X 2=38)$. (Table 2). Beard, eyebrow \& eyelash hair loss were reported in $10 \%$ of the cases $\left({ }_{5}, 8\right)$. In our study eyebrow \& eyelash hair loss were seen in $153 \&$ 137 patients, respectively ( $16 \% \& 14.4 \%$ ) of our cases, in which 105 of them complained of both eyebrow and eyelash hair loss. Association of alopecia areata with other dermatologic disorders such as atopic dermatitis, vitiligo, wart \& pityriasis alba were observed in $32,24,24 \& 8$ cases, respectively. Amongst endocrine disorders, thyroid diseases are the commonest that has been described as associated with alopecia areata, but the issued values were different. In the greatest study reported till now, Muller has found the evidences of different types of thyroid disease in $8 \%$ of 736 patients in compare to the less than $2 \%$ of the control population in North America $\left({ }_{2}, 7,24,25\right)$. Eczema and asthma or both found in $18 \%$ of the children and $9 \%$ of the adults with alopecia areata and it is revealed that $22 \%$ of the children with alopecia totalis are atopic. In Japan, Ikeda found the incidence of atopy $10 \%$, in whom the onset of the disease has usually been in childhood $\&$ the duration of the disease more than 10 years. The association of other autoimmune diseases such as sjogren's syndrome, lichen planus, lupus erythematous, ulcerative colitis, lichen sclerosis atrophicus, poly-myalgia rheumatica, myasthenia gravis, pernicious anemia, scleroderma, thymoma, pyoderma gangrenosum, agammaglobulinemia, autoimmune haemolytic anaemia \& rheumatoid arthritis with alopecia areata has been reported $\left({ }_{6,24},{ }^{26}\right)$. There is also association between alopecia areata, vitiligo \& type of fingertip lines $(3,11,15,22)$. Muller \& his colleagues realized that about $4 \%$ of the patients with alopecia areata have vitiligo as well, while in their control group this association was only $1 \%$ (15). Amongst those 
who had dark hair, $275(37.37 \%)$ cases had exclusive scalp hair loss \& $200(24.27 \%)$ cases complained of exclusive body hair loss. In compare, those who had light hair, 24 $(21.42 \%)$ cases complained of exclusive scalp hair loss and $39(34,82 \%)$ cases had exclusive body hair loss. Association between alopecia areata $\&$ hair color a significant relation was seen so that, dark hair patients in compare to those with light hair had more exclusive scalp hair loss while those with light hair color suffered more from exclusive body hair loss. Amongst those with light complexion, 32 cases (21.05\%) complained of exclusive scalp hair loss \& 48 cases $(31.65 \%)$ had exclusive body hair loss. those with bronzed skin complex complained of exclusive scalp hair loss \& exclusive body hair loss of 203 (32.53\%) \& 175 (28.04\%)

respectively. In between those patients with dark complexion $64(36.36 \%)$ persons had exclusive scalp hair loss \& 16 cases $(9.09 \%)$ had exclusive body hair loss. In this way, between the location of alopecia areata $\&$ the patient's skin color a significant relationship was seen. Patients who had dark skin were with more scalp alopecia areata, while those who had light hair were more rate of alopecia areata in body. There was no significant relation between alopecia areata \& the number of extracted teeth. But there was a positive significant relation between association of alopecia areata \& the number of decayed or infected teeth. Association between nail disorders were also seen more with scalp alopecia areata than with body $(\mathrm{p}<0.05)($ Tables 3-4-5).

\section{Figure 1}

Table 1: Frequency of localized hair loss area according to sex in 952 patients with alopecia areata (AA)in out patient of Kerman a south province of Iran.

\begin{tabular}{|l|l|l|l|}
\hline \multicolumn{1}{|c|}{ Sexes } & Male & Female & Total \\
\hline $\begin{array}{l}\text { Localization of alopecia A) } \\
\begin{array}{l}\text { Bipolar Alopecia Areata } \\
\text { (Both scalp \& body) }\end{array}\end{array}$ & $317(\% 76.5)$ & $97(\% 23.4)$ & $414(\% 43.4)$ \\
\hline Exclusive scalp alopecia A (A.A) & $175(\% 58.5)$ & $124(\% 41)$. & $299(\% 31.4)$ \\
\hline Exclusive body hair loss (AA) & $199(\% 83.2)$ & $40(\% 16.7)$ & $239(\% 25.1)$ \\
\hline Total & $691(\% 72.6)$ & $261(\% 27.4)$ & $952(\% 100)$ \\
\hline
\end{tabular}

\section{Figure 2}

Table 2: Frequency site of localized hair loss according to age in 952 patients with alopecia areata (AA)who has been referred to dermatology out patients of specially clinic in Kerman s south province of Iran .

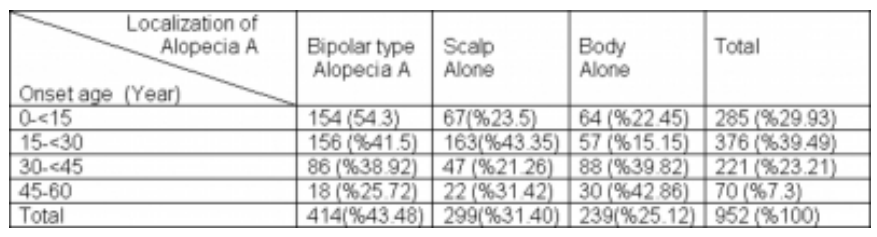

\section{Figure 3}

Table 3: Over all pattern of alopecia areata according to the extent of scalp or body hair loss in 952 patients with alopecia areata referred to dermatology out patient in Kerman

\begin{tabular}{|c|c|c|c|c|c|c|}
\hline $\begin{array}{l}\text { Extent of body hair } \\
\text { loss } \\
\text { Due to alopecia } \\
\text { areata }\end{array}$ & $\begin{array}{l}\text { Body } \\
\text { AA } \\
\text { Stage } 0\end{array}$ & $\begin{array}{l}\text { Body } \\
\text { AA } \\
\text { Stage } 1\end{array}$ & $\begin{array}{l}\text { Body } \\
\text { AA } \\
\text { Stage } 2\end{array}$ & $\begin{array}{l}\text { B ody } \\
\text { AA } \\
\text { Stage } 3\end{array}$ & $\begin{array}{l}\text { Body } \\
\text { AA } \\
\text { Stage } 4\end{array}$ & Total \\
\hline $\begin{array}{l}\text { Extent of scalp (AA) } \\
\text { Hair loss grades }\end{array}$ & & & & & & \\
\hline Scalp AA grade 0 & $0(0 \%)$ & \begin{tabular}{|l|}
$168(\% 7$ \\
$0.29)$ \\
\end{tabular} & \begin{tabular}{|l}
$56(\% 23$ \\
$43)$
\end{tabular} & $\begin{array}{l}15(\% 6 . \\
27)\end{array}$ & $0 .(0 \%)$ & $\begin{array}{l}239(\% 2 \\
5.10) \\
\end{array}$ \\
\hline Scalp AA grade 1 & \begin{tabular}{|l|}
$232(\% 5$ \\
$5.5)$ \\
\end{tabular} & $\begin{array}{l}48(\% 11 \\
48)\end{array}$ & $\begin{array}{l}106(\% 2 \\
5.35)\end{array}$ & $\begin{array}{l}32 .(\% 7 \\
65)\end{array}$ & $0(0 \%)$ & $\begin{array}{l}418(\% 4 \\
3.9)\end{array}$ \\
\hline Scalp AA grade 2 & $67(\% 40$ & $\begin{array}{l}24 \\
54)\end{array}$ & $\begin{array}{l}41 \\
34)\end{array}$ & $25(\% 15$ & $\begin{array}{l}8 \\
4)\end{array}$ & $165(\% 1$ \\
\hline Scalp AA grade 3 & $0(0 \%)$ & $\begin{array}{r}8 \\
\text { 4) }\end{array}$ & $\begin{array}{r}48 \\
48)\end{array}$ & $33 / \% 34$ & $\begin{array}{l}8 \\
44)\end{array}$ & \begin{tabular}{|r|}
97 \\
$18)$
\end{tabular} \\
\hline Scalp AA grade 4 & $0(0 \%)$ & $0(0 \%)$ & $0(0 \%)$ & $31(\% 93$ & $\begin{array}{l}2 \\
6)\end{array}$ & $\begin{array}{l}33 \\
6)\end{array}$ \\
\hline Total & $299 / \% 3$ & $2481 \% 2$ & $251(\% 2$ & $136(\% 1$ & $18(\% 1$. & $952(\% 1$ \\
\hline
\end{tabular}

\section{Figure 4}

Table 4: The frequency of nail changes in compare to hair loss area in 952 out patients of alopecia areata in Kerman a south province of Iran

\begin{tabular}{|l|l|l|l|l|l|l|}
\hline $\begin{array}{c}\text { Nail } \\
\text { Site of } \\
\text { Hair loss (AA) }\end{array}$ & $\begin{array}{c}\text { No } \\
\text { Abnormality }\end{array}$ & Pitting & Ridging & Dystrop & $\begin{array}{l}\text { Multiple } \\
\text { Lesion }\end{array}$ & Total \\
\hline $\begin{array}{l}\text { Combined hair loss } \\
\text { C (Scalp \& body) }\end{array}$ & $56(\% 14.35)$ & $48(\% 12$ & $91(\% 33$ & $8(\% 2.0$ & $187(\% 4$ & $390(\% 4$ \\
\hline $\begin{array}{l}\text { Exclusive scalp } \\
\text { Hair loss }\end{array}$ & $88(\% 29.43)$ & $32(\% 10$ & $98(\% 32$ & $16(\% 5$ & $65(\% 21$ & $299(\% 3$ \\
\hline $\begin{array}{l}\text { Exclusive body } \\
\text { hair loss }\end{array}$ & $48(\% 20.77)$ & 0 & $103(\% 4$ & 0 & $80(\% 34$ & $231(\% 2$ \\
\hline Total & $192(\% 20.86)$ & $80(\% 8$ & $292(\% 3$ & $24(\% 2$. & $332(\% 3$ & $920(\% 1$ \\
\hline
\end{tabular}

\section{Figure 5}

Table 5: The frequency of the number of decayed teeth in compare to the site of alopecia in 952 patients with alopecia areata referred to dermatology out patient clinics in Kerman a south province of Iran .

\begin{tabular}{|l|l|l|l|}
\hline \multicolumn{1}{|c|}{$\begin{array}{c}\text { Number of } \\
\text { decayed }\end{array}$} & $\begin{array}{l}<2 \text { teeth } \\
\text { infected } \\
\text { infected }\end{array}$ & Total \\
Site of hair loss (AA) & & & \\
\hline $\begin{array}{l}\text { Bipolar type hair loss (scalp } \\
\text { \&boy) }\end{array}$ & 33 & $253(\% 88.46)$ & 286 \\
\hline Exclusive scalp hair loss(AA) & $53)$ & $124(\% 76.07)$ & $163(\% 27.16)$ \\
\hline Exclusive body hair loss(AA) & $16(\% 10.59)$ & $135(\% 89.40)$ & $151(\% 25.16)$ \\
\hline Total & $88(\% 14.66)$ & $512(\% 85.33)$ & $600(\% 100)$ \\
\hline
\end{tabular}

\section{References}

1. Arnold HL. Alopecia areata: prevalence in Japanese and prognosis after reassurance. Arch Dermatol Syphylol 1952; 66:191-97.

2. Galbraith GMP, Thiers BH, Fudenberg HH .Guidelines of Care for Alopecia Areata. This report reflects the best 1 . Alopecia areata and auto-immunity. Br J Dermatol 
1981;105:153-7.

3. Hachem-Zadeh S, Brautbar C, Cohen T. HLA and alopecia areata in Jerusalem. Tissue Antigens 1981; 18: 71-4.

4. Emel Öztürk ERKEK (öğr. üyesi) Yrd. Doç.Dr. Ahu BIROL (öğr. üyesi) Gülcan Saylam Kurtipek. Yeter Bağci. Fatma Tunçez ,Gulcan Sylam Kurtipek, Yeter Bagcl Mukadder, Kucak .The efficacy of intermittent low dose systemic corticosteroid in the treatment of alopecia areata .Turk J Med Sci 34 (2004) 55-58 .

5. Seiter S, Ugurel S, Tilgen W et al. High-dose pulse corticosteroid therapy in the treatment of severe alopecia areata . Dermatology 202:230-4, 2001.

6. Gilhar A, Krueger GG. Hair growth in scalp grafts form patients with alopecia areata and alopecia universalis grafted onto unde mice. Arch Dermatol $1987 ; 123$ : 44-50.

7. Muller SA, Winkelmann RK. Alopecia areata. Arch Dermatol 1963; 88:290-97.

8. Tan E, Tay YK, A cliam CY, A clinical study of childhood alopecia areata Singapore. Ped Dermatol 19: 298-301, 2002.

9. Madani S, Shapiro J. Alopecia areata update. J Am Acad Dermatol 42: 549- 66, 2000.

10. Valikhani M, Bazegari M Aghaeii nia N.

Epidemiological compare study on alopecia areata varieties Skin disease seasonal journal of Iranian dermatological association 2001 pp 11-14 (farsi).

11. Ikeda T.A new classification of alopecia areata.

Dermatolgy 1987;131:421-45.

12. Verbov J. Clinical significance and genetics of epidermal ridges: A review of

dermatolgyhics. J Invest Dermatol 1970;54:261-71.

13. Shapiro J, Madani S. Alopecia areata diagnosis and mangement. Int J Dermatol 38 (Suppl 1): 19-24,1999. 14. Muller SA, Winkelmann RK: Alopecia areata : An evaluation of 736 patients.

Arch Dermatol 88: 290-97, 1963.

15. Kern F. Laboratory evaluation of patients with alopecia areata In: Brown AC (ed). First human hair symposium. New York : Medcom,1974:222-40.

16. Kianto U, Reunala T, Karvonen J, et al. HLA-B12 in alpoecia areata. Arch Dermatol 1977;113: 1716.

17. Muller SA, Mitchell Aj, Bacon Gem et al, Alopecia areata, endocrine function and

autoantibodies in patients 16 years of age or younger. J Am Acad Dermatol 1987; 17: 57-61.

18. Hay IC, Jamieson M, Ormerod AD. Randomized trial of aromatherapy, Successful treatment for alopecia areata. Arch Dermatol 1998;134:1349-52.

19. Schenk Fa, Schneider P, Brown Ac. Vitiligo. In: Brown AC, Crounse RG (eds). Hair, trace elements and human disease. New York:Praeger, 1980:334-42.

20. Rook A, Dawber R: Disease of the Hair and Scalp. Oxford., Blackwell Scientific, 1982. 21. Fiedler V. Alopecia areata. Arch Dermatol 128: 1519-29,1992.

21. Verbov JL. Dermatologic and other findings in alopecia areata and psoriasis. Br J Clin Pract 1968; 22:257-59.

22. Alabdulkareem AS, Abahussein AA, Okoro A. Severe alopecia areata treated with systemic coricosteroids. Int J Dermatol 37: 622-4,1998.

23. Walker S, Rothman S: Alopecia areata: A statistical study and consideration of endocrine influences. J invest Dermatol 14:403, 1950.

24. MacDonald N: Alopecia areata: identification and current treatment approaches.

Dermatol Nurs 1999 Oct; 11(5): 356-9, 363-6.

25. Madani S, Shapiro J: Alopecia areata update. J Am Acad Dermatol 2000 Apr; 42(4): 549-66; quiz 567-70. 


\section{Author Information}

Sadollah Shamsadini, M.D.

Professor of dermatolology, Department of Dermatology, Kerman University of medical sciences

Shahriar Sadre Eshkavary, M.D.

Assistant professor of dermatology, Department of Dermatology, Gilan University of medical sciences

Vahidreza Sepehr, M.D.

Assistant professor of Dermatology, Department of Dermatology, Kermanshah University of medical sciences 